\title{
ポリエチレンの塩素化に関するモンテカルロシミュレーション
}

\author{
森 和英*1 ・荒川 務*2・田村 佳子*2 ・橴佐 義博*3
}

（受付 1994 年 9 月 8 日・蕃査終了 1994 年 12 月 16 日)

\begin{abstract}
要 旨 塩素化ポリエチレンの生成プロセスであるポリエチレンの塩素置換反応において, 生成する塩素化ポリ エチレンの塩素分布をイジングモデル類似の簡単なモデルハミルトニアンを用いたモンテカルロ法により検討し た. 初めに，モデルハミルトニアン中の塩素間の相互作用の大きさに関するパラメー夕の値は，分子軌道法を用い 見皘った. さらに，モデルハミルトニアン中で合成環境に基づく有効パラメータ值はNMR 実測値より決定した。 塩素の各パターンごとの存在確率のシミュレーション計算結果と NMRによる実測値とは, 良い対応を示した。 以 上より塩素間の相互作用を 2 体の相互作用項の和で表現できることが明らかとなった，さらに，本モデリング手法 は, 他の置換反応や吸着反応系等への適用も可能であり，有効なシミュレーション手法であることが明らかとなっ た.
\end{abstract}

\section{1 楮言}

塩素化ポリエチレン (CPE) の熱安定性を向上させる ことは，実用上極めて重要である，一方，CPE の熱分解 は分子鎖中のミク口構造, すなわち枝分かれ構造や，分 子鎖中の塩素分布の不規則性などに著しい影響を受ける ことが知られている゙。これらに関する計算化学的手法 を用いた研究としてはポリ塩化ビニル (PVC)について 有限系のモデル化合物について分子軌道法による構造の 安定性の検討がなされている2゙, 3).

本研究では, CPE の熱安定性と塩素分布との関係を明 らかにするため Fig. 1 のようにCPE の一次構造である 分子鎖に沿った塩素分布について CPE の製造プロセス の反応シミュレーションを実施した. CPE はポリエチレ ンの塩素置換反応によって合成されるが, この反応過程 を動力学的に追っていくことは系嚆分子の集合体であ ることと, 途中に化学反応が介在するため現状では極め て困難であると思われる．そこで, 反応の終状態におけ るCPE の塩素分布に着目し、これが反応の経路によら ず生成系の熱力学的安定性のみを反映したものであると 仮定し, CPE の塩素分布の解析に磁性体のスピン分布や 相転移に関する解析法として良く知られているイジング モデル4を応用し、メトロポリス法を用いたモンテカル ロ計算》)でのシミュレーションを試みた。なお，モデル ハミルトニアン中の塩素間の相互作用の大きさに関する

\footnotetext{
*1 自宅（亚169 東京都新宿区高田馬場 3-22-3 第 2 みづほ荘）

*2 昭和電工 (株)川崎樹脂研究所 ( 3210 川崎市川崎区干鳥町 3-2)

*3 昭和電工(株)生産技術部（西105 東京都港区芝大門 1-13-9）
}

パラメータの評価は, 半経験的分子軌道法プログラム MOPAC Ver. $5^{6)}$ (PM3) $)^{\text {) }}$ を用い見積った。

シミュレーションの結果と比較する CPE の塩素分布 に関する実測値としては, ${ }^{13} \mathrm{C}$ NMR の測定を行い, CPE 中の連続した五つの炭素に関する塩素分布パターンの存 在確率として, Table 1 に示すような実験結果が得られ た. 表中の分布パターンの表記法での 0 と 1 は, 塩素が ついていない炭素を0，塩素がついているすのを1とし ている.この測定結果から明らかなように, 得られた塩 素分布には塩素-塩素間の相互作用の影響が認められ, 塩素間の相互作用の効果を考虑することが必要であると 言える.なお, 存在比として,（）付きで示した值は二 つのパターンを分離できなかったため両者の和の值を示 した.

\section{2 計算方法}

\section{1 モデルハミルトニアンの設定}

ポリエチレン $(\mathrm{PE}) 1$ 分子が, $n$ 分子の塩素供与体 X-Clによって塩素置換される反応式を, 次式のように 表す. 実際の合成は $\mathrm{X}-\mathrm{Cl}$ として塩素ガス $\mathrm{Cl}_{2}$ を用いて いるが，合成環境に関する情報をシミュレーション結果

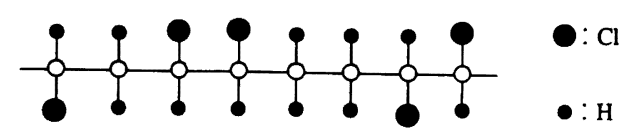

Fig. 1. Schematic picture of chlorinated polyethylene (CPE). 
Table 1. The chlorine distribution results experimentally derived by ${ }^{13} \mathrm{C}$ NMR for CPE

\begin{tabular}{|c|c|c|c|}
\hline \multirow{2}{*}{$\frac{N^{a)}}{0}$} & \multirow{2}{*}{$\frac{\text { Pattern }}{[00000]}$} & \multicolumn{2}{|c|}{ Percentage $[\%]$} \\
\hline & & 26.03 & 26.03 \\
\hline \multirow{3}{*}{1} & {$[10000]$} & 14.61 & \multirow{3}{*}{44.95} \\
\hline & {$[01000]$} & 18.65 & \\
\hline & {$[00100]$} & 11.69 & \\
\hline \multirow{6}{*}{2} & [10001] & 3.11 & \multirow{6}{*}{25.50} \\
\hline & [10010] & $(9.95)$ & \\
\hline & [11000] & (9.95) & \\
\hline & [01100] & 3.57 & \\
\hline & {$[10100]$} & 5.59 & \\
\hline & [01010] & 3.28 & \\
\hline \multirow{4}{*}{3} & [11001] & 0.93 & \multirow{4}{*}{3.32} \\
\hline & [11010] & $(1.65)$ & \\
\hline & [01101] & (1.65) & \\
\hline & {$[10101]$} & 0.74 & \\
\hline \multirow{3}{*}{4} & [01111] & 0.00 & \multirow{3}{*}{0.19} \\
\hline & [10111] & 0.00 & \\
\hline & [11011] & 0.19 & \\
\hline
\end{tabular}

๑) $N$, number of chlorines.

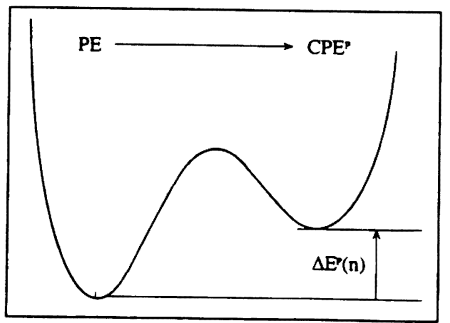

Fig. 2. The concept of the chlorination process of polyethylene.

\section{に取り込むため，便宜的に仮想分子に置き換えた。}

$$
n \cdot \mathrm{X}-\mathrm{Cl}+\mathrm{PE} \rightarrow \mathrm{CPE}^{\mathrm{P}}(n)+n \cdot \mathrm{X}-\mathrm{H}
$$

ここで, 上付き添え字の $\mathrm{P}$ は塩素の分布の仕方による違 いを表す．これを反応ポテンシャルモデルで表すと Fig. 2 のように書ける。実際には, 塩素含有度に関係するn と分布パターンを意味する $\mathrm{P}$ の異なるさまざまな生成 系が存在している.

以上のモデル化に基づいた, 系のモデルハミルトニア ンの導出過程を以下に示す. まず, 生成系の熱力学的安 定性は $\Delta E^{\mathrm{P}}(n)$ で評価できるが，これは反応式右辺の全 エネルギーから左辺の全エネルギーを引いた次式で与え られる。

$$
\Delta E^{\mathrm{P}}(n)=\left\{E_{\mathrm{CPE}}^{\mathrm{P}}(n)+n \cdot E_{\mathrm{X}-\mathrm{H}}\right\}-\left\{n \cdot E_{\mathrm{X}-\mathrm{Cl}}+\mathrm{E}_{\mathrm{PE}}\right\}
$$

右辺を $X$ に依存している項と, 依存していない項にま
Table 2. The pattern of mutual interaction parameters $V_{i j}^{\mathrm{P}}$

\begin{tabular}{ccccc}
\hline \hline \multicolumn{1}{c}{$j=$} & $i+1$ & $i+2$ & $i+3$ & $i+4$ \\
\hline$V_{i j}\left(P_{i} P_{j}=1\right)$ & $\uparrow \uparrow$ & $\uparrow 0 \uparrow$ & $\uparrow 00 \uparrow$ & $\uparrow 000 \uparrow$ \\
$V_{i j}\left(P_{i} P_{j}=-1\right)$ & $\uparrow \downarrow$ & $\uparrow 0 \downarrow$ & $\uparrow 00 \downarrow$ & $\uparrow 000 \downarrow$ \\
\hline
\end{tabular}

$$
\begin{aligned}
& \text { とめると, } \\
& \Delta E^{\mathrm{P}}(n)=\Delta E_{\mathrm{CPE}}^{\mathrm{P}}(n)-n \cdot \alpha_{\mathrm{X}} \\
& \text { ただし, } \\
& \Delta E_{\mathrm{CPE}}^{\mathrm{P}}(n)=E_{\mathrm{CPE}}^{\mathrm{P}}(n)-E_{\mathrm{PE}}
\end{aligned}
$$

および $\alpha_{\mathrm{X}}=E_{\mathrm{X}-\mathrm{C}}-E_{\mathrm{X}-\mathrm{H}}$ とおいた。

一方, $\Delta E_{\mathrm{CPE}}^{\mathrm{P}}(n)$ は, 物理的な意味から形式的に (2) 式 のように表せる.

$$
\Delta E_{\mathrm{CPE}}^{\mathrm{P}}(n)=n \cdot h+V^{\mathrm{P}}(n)
$$

ただし，

$h$, 単一塩素置換によるエネルギー变化

$V^{\mathrm{P}}(n), n$ 個の塩素間の相互作用

(2) 式を(1) 式に代入して $h-\alpha_{\mathrm{x}}$ を有効值 $h^{\mathrm{erf}}$ で置き換 えれば, 次式が得られる。

$$
\Delta E^{\mathrm{P}}(n)=n \cdot h^{\mathrm{eff}}+\sum V^{\mathrm{P}}(n)
$$

ここで，定義された $h^{\mathrm{err}}$ は，モデル化のため取り込め ない供与体の衝㔖頻度や塩素供与能力などの合成反応条 件などの環境を、反映させるためパラメータとして導入 した.

さらに, $n$ 体の相互作用項 $V^{\mathrm{P}}(n)$ を，次のように相互 作用の加成性を仮定して二体の相互作用の和で近似す る.すなわち，

$$
V^{\mathrm{P}}(n) \leftrightharpoons \sum_{i>j} V_{i j}^{\mathrm{P}}
$$

ここで $i, j$ は塩素についての和を意味する.これより， (3) 式は (4) 式のように書ける.

$$
\Delta E^{\mathrm{p}}(n)=n \cdot h^{\mathrm{err}}+\sum_{i>j} V_{i j}^{\mathrm{p}}
$$

イジングモデル類似の取り扱いを可能とするため, $\mathrm{CPE}$ 系の波動関数 $\left|\Psi_{\mathrm{P}}\right\rangle$ を以下のように表現する.

$\left|\Psi_{\mathrm{P}}\right\rangle=\left|P_{1}, P_{2}, P_{3}, \cdots\right\rangle$

ただし $P_{i}=1(\uparrow), 0(0),-1(\downarrow)$

ここで，添字 $P_{i}$ は炭素銷上の $i$ 番目の炭素に塩素が分 子平面の上側についているとき 1 ，下側についていると き -1 , 塩素がついていないとき0をとるすのとする. $\Delta E^{\mathrm{P}}(n)$ を固有値とするモデルハミルトニアン $\hat{H}$ は以 下のように書ける.

$$
\hat{H}=h^{\mathrm{eff}} \sum_{i} \hat{n}_{i}+\sum_{i} V_{i j}^{\mathrm{P}} \hat{n}_{i} \hat{n}_{j}
$$

ここで $\hat{n}_{i}$ は数演算子として定義し, 次式が成立するも のとする.

$$
\hat{n}_{i}\left|\Psi_{P}\right\rangle=\left|P_{i}\right| \cdot\left|\Psi_{\mathrm{P}}\right\rangle
$$


相互作用項 $V_{i j}^{\mathrm{P}}$ は Table 2 のように，隣接 4 ステップ計 8 種類を考虑した。

系のシュレディンガー方程式は次式で与えられる.

$$
\hat{H}\left|\Psi_{\mathrm{P}}>=E_{\mathrm{P}}\right| \Psi_{\mathrm{P}}>E_{\mathrm{P}}=\Delta E^{\mathrm{P}}(n)
$$

\section{2 モンテカルロ計算の概略}

前節に示したように，本研究では塩素化のプロセスを イジングモデル類似の体系にモデル化し, 系の状態は (5) 式の波動関数で記述し，その状態変化に伴うエネル ギー変化は (6) 式のハミルトニアンを用いて (8) 式から 計算できる．ここで通常のイジングモデルとの違いは, 各サイトにおけるとりうる状態の数と考虑した相互作用 の種類の二点である. まず, 状態の数についてはイジン グモデルではスピンのアップ, ダゥンの 2 通りである が，本ヶースでは炭素に塩素がついていない場合の塩素 なし (0), 塩素が上側についた上付き (1), 塩素が下側に ついた下付き $(-1)$ の 3 通りあり, メトロポリス法にお ける状態の実現確率は三状態問題として与えられ, 状態 の決定方法は一段階とはならない，そこで本計算では多 段方式を用いている．すなわち，第一段階では塩素の脱
着に関する選択を行い「着」の場合はさらに，第二段階 で上付き (1) か下付き $(-1)$ かの決定を行った。この手 続きは分配関数に三状態を考慮することにより,メト口 ポリス法の目的である熱平衡状態の達成が実現可能であ る. 次に相互作用項については, 通常のイジングモデル では最隣接からの 1 種類であるが, 本計算では前節で述 べたように 8 種類の相互作用を考慮している。しかしな がら、これに関してはプログラムのアルゴリズム上はほ とんど同様な取り扱いが可能である.

以下に計算手順の概略を示す。

（1）初期状態はポリエチレンとし，参照セルとして 炭素数にして 80 個の鎖を用いる.

(2) 順次炭素上の塩素の付き方を変えたときの系の エネルギー変化を算出し, メトロポリス法にて状態の選 択を行う。なおこの際，周期的境界条件を用いて末端の 影響を除いた。

（3）（2）の過程を系が十分に熱平衡状態に近づくま で繰り返す．この際塩素含有值により収束の判定を行っ た.

Table 3. The total energies of the various model compounds

\begin{tabular}{|c|c|c|c|c|c|}
\hline Pattern & Total energy & $\Delta E_{\mathrm{CPE}}^{\mathrm{P}}(n)$ & $\Delta E_{\mathrm{CPE}}^{\mathrm{P}}(n)$ & $V^{\mathrm{P}}$ & $\sum V_{i j}^{\mathrm{P}}$ \\
\hline PE & -55.04254 & & & & \\
\hline$[00 \uparrow 00]$ & -60.43599 & -5.39345 & -5.39345 & & \\
\hline$[0 \uparrow 000]$ & -60.45764 & $(-0.02165)$ & $(-0.02165)$ & & \\
\hline$[\uparrow 0000]$ & -60.45034 & $(-0.01435)$ & $(-0.01434)$ & & \\
\hline$[\downarrow 00 \uparrow 0]$ & -65.98316 & -10.94062 & -10.90462 & -0.118 & \multirow{8}{*}{$V_{i j}^{\mathrm{P}}$} \\
\hline$[\uparrow 00 \uparrow 0]$ & -65.63428 & -10.59174 & -10.55574 & 0.231 & \\
\hline$[\downarrow 000 \uparrow]$ & -65.88010 & -10.83756 & -10.80886 & -0.022 & \\
\hline$[\uparrow 000 \uparrow]$ & -65.60644 & -10.56390 & -10.53520 & 0.252 & \\
\hline$[0 \downarrow 0 \uparrow 0]$ & -65.84446 & -10.80192 & -10.75862 & 0.028 & \\
\hline$[0 \uparrow 0 \uparrow 0]$ & -63.65004 & -8.60750 & -8.56420 & 2.223 & \\
\hline$[0 \downarrow \uparrow 00]$ & -64.53542 & -9.49288 & -9.47123 & 1.316 & \\
\hline$[0 \uparrow \uparrow 00]$ & -63.86544 & -8.82290 & -8.80125 & 1.986 & \\
\hline$[\uparrow 0 \downarrow 0 \uparrow]$ & -70.93771 & -15.89517 & -15.86647 & 0.314 & 0.308 \\
\hline$[\downarrow 0 \uparrow 0 \uparrow]$ & -69.02482 & -13.98228 & -13.95358 & 2.227 & 2.229 \\
\hline$[\uparrow 0 \uparrow 0 \uparrow]$ & -66.67387 & -11.63133 & -11.60263 & 4.578 & 4.697 \\
\hline$[\downarrow 0 \downarrow 0 \uparrow]$ & -69.02482 & -13.98228 & -13.95358 & 2.227 & 2.229 \\
\hline$[\downarrow \downarrow 0 \uparrow 0]$ & -69.37984 & -14.33730 & -14.27965 & 1.901 & 1.896 \\
\hline$[\uparrow \downarrow 0 \uparrow 0]$ & -69.73036 & -14.68782 & -14.63017 & 1.550 & 1.575 \\
\hline$[\uparrow \uparrow 0 \uparrow 0]$ & -66.98699 & -11.94445 & -11.88680 & 4.294 & 4.440 \\
\hline$[\downarrow \uparrow 0 \uparrow 0]$ & -67.92437 & -12.88183 & -12.82418 & 3.356 & 3.421 \\
\hline$[\downarrow \downarrow 00 \uparrow]$ & -69.39501 & -14.35247 & -14.30212 & 1.878 & 1.846 \\
\hline$[\uparrow \downarrow 00 \uparrow]$ & -69.83826 & -14.79572 & -14.74537 & 1.435 & 1.450 \\
\hline$[\downarrow \uparrow 00 \uparrow]$ & -69.76373 & -14.72119 & -14.67084 & 1.510 & 1.525 \\
\hline$[\uparrow \uparrow 00 \uparrow]$ & -68.87802 & -13.83548 & -13.78513 & 2.395 & 2.469 \\
\hline
\end{tabular}

( ): calibration value $[\mathrm{kcal} / \mathrm{mol}]$ 
本研究での目的は, 熱平衡状態でのミクロな塩素分布 のパターン別の存在確率を得ることにあるので,ここま での計算はいわば前処理であり, さらに以下の計算を行 j.

（4）（2）の過程を繰り返しながら, 発生する参照セル を熱平衡状態における生成塩素化ポリエチレンのサンプ ルとし，各塩素分布のパターン別の集計をとる.

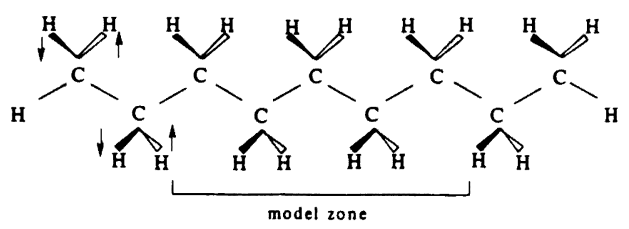

Fig. 3. The model structure for the original polyethlene.

Table 4. Calculation results of mutual interaction parameters $V_{i j}^{\text {p }}$

\begin{tabular}{crc}
\hline \hline$j$ & $\uparrow \downarrow$ & $\uparrow \uparrow$ \\
\hline$i+1$ & 1.316 & 1.986 \\
$i+2$ & 0.028 & 2.223 \\
$i+3$ & -0.118 & 0.231 \\
$i+4$ & -0.022 & 0.252 \\
\hline
\end{tabular}

$[\mathrm{kcal} / \mathrm{mol}]$

\section{3 結果と考察}

\section{1 塩素間相互作用パラメータの算出}

以下に相互作用パラメータの算出手順とその結果を示 す.まず分子軌道法計算によって最適化された安定構造 に関するエネルギーの計算結果を Table 3 に示す。計算 は, Fig. 3 のように炭素数 9 個の all trans 型の直鎖上一 次構造に対し，中央の五つの炭素の塩素置換体について 行った。ここで同一炭素への塩素 2 置換体はかなり不安 定であると考え, シミュレーションの対象からは除外し た. Table 3 中の $\Delta E_{\mathrm{CPE}}^{\mathrm{P}}(n)$ および $\Delta E_{\mathrm{CPE}}^{\prime \mathrm{P}}(n)$ はそれぞれ PE と CPE の全エネルギー差と, 塩素置換位置補正後の 全エネルギー差を意味する.

さらに $V^{\mathrm{P}}$ は塩素間の相互作用であり, 次のようにし て見積った。例えば，2塩素置換体については，1塩素置 換体の全エネルギー差 $\Delta E_{\mathrm{CPE}}^{\mathrm{P}}(n)$ を2 倍したエネルギー 値と 2 置換体の位置補正後の $\Delta E^{\prime}{ }_{\mathrm{CPE}}^{\mathrm{P}}(n)$ との差より求め た。これを二体の相互作用之呼ぶ。 3 塩素置換体につい ては同様な手続きで得られた $V^{\mathbf{P}}$ 值と三体の相互作用項 を, 二体の相互作用の和 $\Sigma V_{i j}^{\mathrm{P}}$ として求めた值を併記し た。両者の比較加ら, 塩素間の相互作用に関して加成性 がほぼ成立することが明らかとなり，前節のモデルハミ ルトニアン (6) 式の有効性が確認された.

\section{2 有効パラメータの算出}

Table 1 に示すように, 本合成プロセスでの CPE の炭 素 5 個中の塩素数の期待値である塩素含有度は, 1.07 で

Table 5. Influences of the chlorine distribution on the effective parameter $h^{\text {ef }}$

\begin{tabular}{cccccccc}
\hline \hline$h^{\text {eff }}$ & $\mathrm{S}_{0}{ }^{\mathrm{a}}$ & $\mathrm{S}_{1}{ }^{\mathrm{a}}$ & $\mathrm{S}_{2}{ }^{\mathrm{a})}$ & $\mathrm{S}_{3}{ }^{\mathrm{a}}$ & $\mathrm{S}_{4}{ }^{\mathrm{a})}$ & $\mathrm{S}_{\mathrm{s}}{ }^{\mathrm{a})}$ & $\mathrm{R}^{\mathrm{b})}$ \\
\hline-0.30 & 3.689 & 40.492 & 49.418 & 6.327 & 0.075 & 0.000 & 1.5861 \\
-0.20 & 4.906 & 42.860 & 46.928 & 5.253 & 0.054 & 0.000 & 1.5269 \\
-0.10 & 6.478 & 45.328 & 43.927 & 4.228 & 0.039 & 0.000 & 1.4602 \\
0.00 & 8.296 & 47.369 & 40.854 & 3.456 & 0.025 & 0.000 & 1.3954 \\
0.05 & 9.388 & 48.489 & 38.991 & 3.105 & 0.026 & 0.000 & 1.3589 \\
0.10 & 10.542 & 49.392 & 37.313 & 2.733 & 0.019 & 0.000 & 1.3229 \\
0.15 & 11.881 & 50.135 & 35.487 & 2.480 & 0.016 & 0.000 & 1.2862 \\
0.20 & 13.433 & 50.763 & 33.632 & 2.159 & 0.013 & 0.000 & 1.2456 \\
0.25 & 14.864 & 51.492 & 31.738 & 1.899 & 0.008 & 0.000 & 1.2069 \\
0.30 & 16.438 & 51.872 & 30.023 & 1.657 & 0.011 & 0.000 & 1.1693 \\
0.35 & 18.270 & 52.182 & 28.137 & 1.404 & 0.007 & 0.000 & 1.1269 \\
0.40 & 19.919 & 52.400 & 26.423 & 1.253 & 0.005 & 0.000 & 1.0903 \\
0.45 & 22.038 & 52.255 & 24.611 & 1.090 & 0.006 & 0.000 & 1.0477 \\
0.50 & 24.117 & 52.108 & 22.830 & 0.942 & 0.003 & 0.000 & 1.0060 \\
0.55 & 25.945 & 51.882 & 21.386 & 0.783 & 0.004 & 0.000 & 0.9702 \\
0.60 & 28.261 & 51.448 & 19.613 & 0.677 & 0.002 & 0.000 & 0.9271 \\
0.65 & 30.533 & 50.738 & 18.163 & 0.565 & 0.002 & 0.000 & 0.8876 \\
0.70 & 32.576 & 50.256 & 16.678 & 0.489 & 0.001 & 0.000 & 0.8508 \\
\hline
\end{tabular}

a) $\mathrm{S}_{N}, N$ substitution compounds. b) $\mathrm{R}$, the ratio substituted for chlorine in $\mathrm{C} 5$ model. 
Table 6. Calculation results of the chlorine distribution for CPE

\begin{tabular}{ccc}
\hline Pattern & Calcd. & Exptl. \\
\hline$[00000]:$ & 24.05075 & 26.03 \\
\hline$[10000]:$ & 17.24825 & 14.61 \\
{$[01000]:$} & 22.48050 & 18.65 \\
{$[00100]:$} & 12.39450 & 11.69 \\
\hline$[11000]:$ & 0.69850 & $(9.95)$ \\
{$[01100]:$} & 0.88975 & 3.57 \\
{$[10100]:$} & 6.30325 & 5.59 \\
{$[01010]:$} & 3.43425 & 3.28 \\
{$[10010]:$} & 8.57500 & $(9.95)$ \\
{$[10001]:$} & 2.97950 & 3.11 \\
\hline$[11100]:$ & 0.01575 & - \\
{$[01110]:$} & 0.00375 & - \\
{$[11010]:$} & 0.18225 & 1.65 \\
{$[11001]:$} & 0.20175 & 0.93 \\
{$[10110]:$} & 0.18025 & $?$ \\
{$[10101]:$} & 0.35750 & 0.74 \\
\hline$[11110]:$ & 0.00025 & - \\
{$[11101]:$} & 0.00150 & - \\
{$[11011]:$} & 0.00275 & 0.19 \\
\hline
\end{tabular}

あった．そこで，モデルハミルトニアン中で導入された $h^{\text {efr }}$ の値は, この塩素含有值を再現するように決定した. 具体的には $h^{\text {er }}$ の値を種々に変更してモンテカルロシ ミュレーションで各置換体の存在確率を求めた (Table 5). その際計算の設定温度は常温 $300 \mathrm{~K}$ とし, 参照セル として炭素数 80 の分子鎖を考虑し，末端効果を除外す るため周期的境界条件を用いている. Table 5 中の $R$ は 塩素含有値であり, $h^{\text {efr }}$ が $0.5[\mathrm{kcal} / \mathrm{mol}]$ の時実測の塩

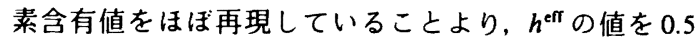
[ $\mathrm{kcal} / \mathrm{mol}]$ と決定した.

\section{3 実湘值との比较検討}

各パターンごとの存在確率の計算結果を実測值ととも に Table 6 に示す。計算値と実測値とを比べると，かな り良い対応を示している. Table 6 中で塩素が二つ隣 合った場合の計算結果は実測値に比べてかなり小さくで ている.これは, 塩素か隣合っている場合の計算で得ら れた相互作用パラメータが, 実際より大きく見積もりす ぎているためだと思われる。これは半経験的分子軌道法 を用いたためでありより精密な分子軌道計算を行うこと により, 改善されることが期待される.

次に, 塩素分布の温度依存性に関する計算結果を Fig. 4 に示す。これより, シミュレーションの設定温度であ る $300 \mathrm{~K}$ 付近では, Fig. 4 中の無置換体 $\mathrm{S}_{0}$ と 2 置換体 $\mathrm{S}_{2}$ の存在確率はかなり近い值を与えており, その大小関倸

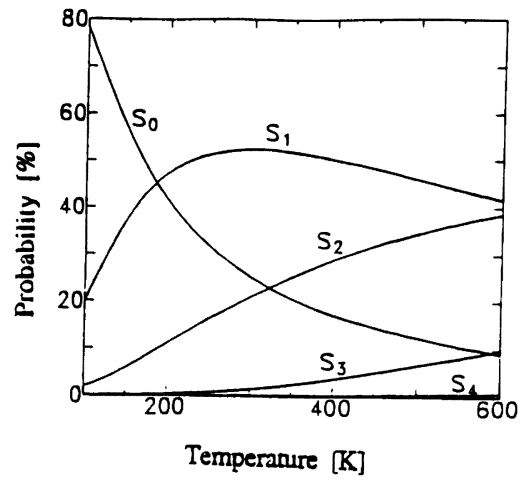

Fig. 4. Temperature dependence of the degree of chlorine content.

を含めて実験値と良い対応を示している，さらにまた実 験環境として温度を上げることにより，この大小関保は 容易に逆転することが予想される.

\section{4 結 論}

本研究は，磁性体におけるスピン分布や相転移に関す る解析法としてょく知られているイジングモデルを化学 反応系であるポリエチレンの塩素置換反応に適用し、メ トロポリス法を用いたモンテカルロ法によって生成した 塩素化ポリエチレンの塩素分布に関するシミュレーショ ンを試みたものである。 その結果, 塩素間の相互作用は 分子軌道法で見積もることによりほぼ二体の相互作用の 和で記述できることが確認された。また簡略なモデルに あかかわらず，NMR の測定実験結果とかなり良い対応 を示した。

本法は他の置換反応や吸着反応系などへの適用は可能 であり, 動力学的な手法に比へて計算に要する負荷は少 なくかなり有効な方法であると思われる.

\section{文献}

1) Z. Mayer, J. Macromol. Sci., C, 10(2), 263 (1974).

2）大植弘義，清水亮作，並木美佐子，飯田健郎，後藤邦夫， 日本化学会秋季年会予稿集 (1991), p. .918.

3) K. S. Minsker, S. V. Kolesov, V. M. Yanborisov, A. A. Berlin, and G. E. Zaikov, Polymer Degradation and Stability. 9, 103 (1984).

4）矢部 孝, 川田重夫, 福田昌弘, “シミュレーション物理 入門", 朝倉書店, 東京 (1989), p. 11; 㞋田盛和, 斎藤信 彦, “統計物理学”, 岩波書店, 東京 (1972) p. 129.

5) 宮武 修, 脇本和昌, “乱数とモンテカルロ法”、森北出 版, 東京 (1978). K. Binder and D. W. Heermann, “Monte Carlo Simulation in Statistical Physics", Springer-Verlag Berlin/Heiderberg Secaucus, NJ (1988), p. 97.

6) MOPAC, Quantum Chemistry Program Exchange, No. 455 (1985). 
7) J. J. P. Stewart, J. Comput. Chem., 10, 209 (1989).

Evaluation of the Chlorine Distribution in Chlorinated Polyethylene by Using Monte Carlo Simulation

Kazuhide MorI*1, Tutomu ARAKawa*2, Keiko TAMURA ${ }^{* 2}$, and Yoshihiro ShIBUSA ${ }^{* 3}$

${ }^{* 1}$ House (3-22-3, Takadanobaba, Shinjuku-ku, Tokyo, 169 Japan)

*2 Kawasaki Plastics Laboratory, SHOWA DENKO (3-2, Chidoricho, Kawasaki-ku, Kawasaki, 210 Japan)

${ }^{*}$ Production Technology Department, SHOWA DENKO (1-13-9, Shibadaimon, Minato-ku, Tokyo, 105 Japan)

The Monte Carlo method was applied to predict the chlorine distribution in chlorinated polyethylene. Mutual interaction coefficients between chlorines were determined from molecular orbital calculations. Effective parameters to account for the synthetic condition were experimentally obtained from NMR measurements. Since the simulation results for chlorine distribution are in good agreement with NMR experiments, we conclude that the approach is a useful method to evaluate the correlation between reactivity and structure. Furthermore, it can also be applied to different substitution and adsorption reactions.

KEY WORDS Monte Carlo Method / Chlorinated Polyethylene / Chlorine Distribution /

Molecular Orbital Calculation /

(Received September 8, 1994: Accepted December 16, 1994)

[Kobunshi Ronbunshu, 52(3), 163-168 (1995)] 